\title{
Concentration dependent cardiotoxicity of terodiline in patients treated for urinary incontinence
}

Simon H L Thomas, P Daniel Higham, Kenneth Hartigan-Go, Farhad Kamali, Peter Wood, Ronald W F Campbell, Gary A Ford

\begin{abstract}
Objective-Terodiline, an antimuscarinic and calcium antagonist drug, was used to treat detrusor instability but was withdrawn in 1991 after provoking serious ventricular arrhythmias associated with increases in the corrected QT interval (QTc). This research was performed to relate drug induced electrocardiographic changes in asymptomatic recipients to plasma concentrations of the $\mathbf{R}(+)$ and S(-) terodiline enantiomers.
\end{abstract}

Setting-Urological and geriatric clinics and wards.

Subjects-Asymptomatic patients taking terodiline in stable dose.

Methods-Electrocardiograms $(50 \mathrm{~mm} / \mathrm{s})$ were collected from patients while they were taking terodiline and compared with ECGs obtained before or after terodiline. QT interval, heart rate corrected QT interval (QTc), and QT dispersion (QTd) were measured. Drug induced electrocardiographic changes were related to plasma concentrations of $R(+)$ and $S(-)$ terodiline.

Results-During terodiline treatment mean QTc and QTd were prolonged (491(43) and $84(35) \mathrm{ms}^{1 / 2}$ ) compared with measurements made off therapy (443 (33) and $42(17) \mathrm{ms}^{1 / 2}$, paired $t$ tests, $P<0.002$ and $P<0.01$ respectively) in the 12 patients in sinus rhythm. The mean $(95 \%$ confidence interval) drug induced increases were 48 (23 to 74$) \mathrm{ms}^{1 / 2}$ for QTc and 42 (13 to 70$) \mathrm{ms}^{1 / 2}$ for QTd. These increases correlated with total plasma terodiline (QTc: $r=0.77, \quad P<0.006$, QTd: $\quad r=0.68, \quad P<0.025)$ and with plasma concentrations of both terodiline enantiomers.

Conclusions-Terodiline increases QTc and QTd in a concentration dependent manner. It is not clear whether this is a stereoselective effect and, if so, which enantiomer is responsible. The results suggest that drug induced torsade de pointes is a type A (concentration dependent) adverse drug reaction.

(Br Heart f 1995;74:53-56)

Keywords: terodiline; cardiotoxicity; electrocardiography
Terodiline hydrochloride is an antimuscarinic drug with calcium antagonist properties ${ }^{1}$ which was used for treating urinary incontinence caused by detrusor instability. ${ }^{2}$ The drug was withdrawn in 1991 after reports of cardiac dysrhythmia including bradycardia, heart block, ventricular fibrillation, and ventricular tachycardia, usually of the torsade de pointes-type ${ }^{34}$ and associated with QT prolongation. Plasma terodiline concentrations were very high in one affected patient. Predisposing factors for terodiline associated torsade de pointes were old age, coexisting ischaemic heart disease, co-prescription of other cardioactive drugs, and hypokalaemia.

Torsade de pointes is associated with abnormal prolongation of the ventricular refractory period which results in a long QT interval on the electrocardiogram and is often drug induced. ${ }^{5}$ Increased dispersion of ventricular recovery may be important in the development of this arrhythmia and indirect evidence indicates that this is reflected by increased dispersion of QT interval durations across the standard 12 lead electrocardiogram. ${ }^{67}$ The relation between torsade de pointes and plasma drug concentrations is uncertain: while torsade may result from overdose of several drugs, ${ }^{5}$ many patients developing drug induced torsade do not have excessive plasma drug concentrations and some consider the arrhythmia to be an idiosynchratic phenomenon. ${ }^{8}$

The effects of terodiline were therefore investigated by collecting electrocardiograms from asymptomatic patients receiving the drug for treatment of urinary incontinence, comparing them with those taken before or after drug treatment, and relating the terodiline induced electrocardiographic changes with plasma concentrations of each terodiline enantiomer.

\section{Patients and methods}

Electrocardiograms $(50 \mathrm{~mm} / \mathrm{s})$ and plasma samples were collected from patients who were taking terodiline in stable dose between 4 and $24 \mathrm{~h}$ after the last dose. This process started in June 1991, when reports of dysrhythmia first appeared, and ended in September 1991 when the drug was withdrawn. Copies of electrocardiograms predating terodiline treatment were also collected, when available, and, if possible, electrocardiography was repeated at 
Table 1 Characteristics of patients in sinus rhythm taking terodiline

\begin{tabular}{lc}
\hline & Mean (range) \\
\hline Age (years) & $73(46-92)$ \\
Height $(\mathrm{cm})$ & $161(150-193)$ \\
Weight $(\mathrm{kg})$ & $61(44-90)$ \\
Daily dose $(\mathrm{mg})^{\star}$ & $38(12 \cdot 5-50)$ \\
Duration of treatment (days) & $231(8-1050)$ \\
Sodium $(\mathrm{mmol} / 1)$ & $139(136-142)$ \\
Potassium $(\mathrm{mmol} / 1)$ & $4 \cdot 1(3 \cdot 4-4 \cdot 8)$ \\
Creatinine $(\mu \mathrm{mol} / 1)$ & $110(89-116)$ \\
Ionised calcium $(\mathrm{mmol} / \mathrm{l})$ & $1 \cdot 30(1 \cdot 25-1 \cdot 32)$ \\
Magnesium $(\mathrm{mmol} / \mathrm{l})$ & $0 \cdot 8(0 \cdot 7-0 \cdot 9)$ \\
Albumin $(\mathrm{g} / \mathrm{l})$ & $41(37-46)$ \\
\hline Values are mean (range). ${ }^{\star}$ Median daily dose was $25 \mathrm{mg}$.
\end{tabular}

least 2 months after terodiline had been discontinued. Each patient's medical details were recorded and the blood sample analysed for plasma drug concentrations, electrolytes, and creatinine.

Electrocardiograms were analysed blind by an independent observer. RR, PR, and QT intervals were measured using a digitiser (Calcomp 9000, Scottsdale, AZ, USA). The QT interval was measured from onset of the QRS complex to the end of the $T$ wave, defined as a return to the TP baseline. In the presence of $U$ waves, the end of the $T$ wave was taken at the TU nadir. Three representative complexes were analysed for those leads of the standard 12 lead electrocardiogram where the $T$ wave could be clearly defined and a mean taken. When the end of the $T$ wave could not be reliably identified the lead was excluded from analysis. The largest QT interval on the 12 lead electrocardiogram (QTmax) was used to derive the corrected QT interval (QTc), which was calculated for each lead using Bazett's formula (QTc $=\mathrm{QT}$ / $\sqrt{ }(\mathrm{RR}$ interval)). QT dispersion (QTd) was determined as the longest minus the shortest QTc on the 12 lead electrocardiogram.

Plasma concentrations of $\mathrm{R}(+)$ - and $S(-)$ - terodiline enantiomers were measured simultaneously by high performance liquid chromatography using a chiral column and an ultraviolet detector. The limit of detection of the method is $25 \mathrm{ng} / \mathrm{ml}$ for each enantiomer and coefficients of variation are $5.5 \%$ for the $\mathrm{R}(+)$-enantiomer at $271 \mathrm{ng} / \mathrm{ml}$ and $7 \cdot 6 \%$ for the $\mathrm{S}(-)$-enantiomer at $173 \mathrm{ng} / \mathrm{ml}$. All samples were analysed in duplicate and without knowledge of the electrocardiographic changes observed in each patient.

\section{Results}

Nineteen patients taking terodiline took part in this study. The electrocardiograms of four
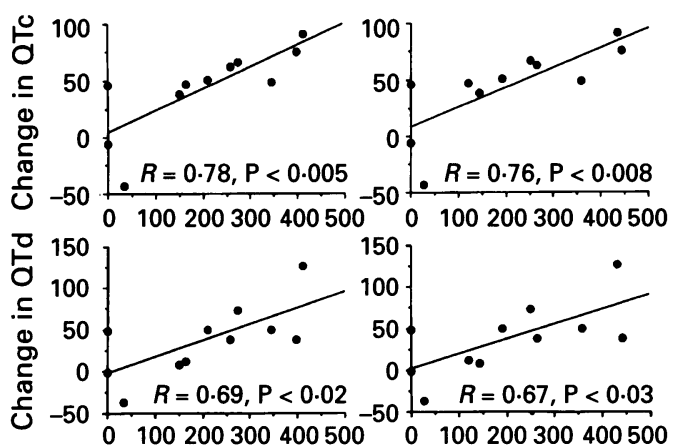

$\mathrm{R}(+)$-terodiline ( $\mathrm{ng} / \mathrm{ml}) \quad \mathrm{S}(-)$-terodiline $(\mathrm{ng} / \mathrm{ml})$

Figure 2 Relation between plasma concentrations of terodiline enantiomers and the extent of drug induced prolongation in corrected $Q T$ intervals (QTc) and $Q T$ dispersion (QTd).

patients with atrial fibrillation were not used as this condition has major effects on QTd. For the 15 patients in sinus rhythm (table 1) electrocardiograms were available before terodiline was started in two patients and after terodiline had been stopped in 11, although one of these had developed atrial fibrillation. Electrocardiograms in sinus rhythm were therefore available during and before or after treatment in 12 patients, of whom 11 agreed to give a blood sample. Of these, one had right bundle branch block and four were taking other drugs which might affect QT interval (dothiepin, imipramine, thioridazine, sotalol), the doses of which were not altered during the study, and five had cardiovascular disease (cerebrovascular disease (three), coronary artery disease (one), and hypertension (one)). Electrocardiograms of two patients receiving terodiline were collected after only 8 and 16 days of treatment, possibly before steady state concentrations and the maximal electrocardiographic effects of the drug would be achieved.

A total of 17 patients gave a blood sample. Plasma concentrations of the two terodiline enantiomers correlated closely $(r=0.99$, $\mathrm{P}<0.0001)$ with a mean (SD) $\mathrm{R}(+)-/ \mathrm{S}(-)-$ ratio of $1.03(0 \cdot 14)$. No significant correlations were observed between daily terodiline dose and the plasma concentration of either terodiline enantiomer. Apparent terodiline clearance, measured as daily dose divided by plasma concentration, varied widely between patients and did not correlate significantly with age in this small group (data not shown).

Terodiline did not affect the PR interval or heart rate but prolonged QTc and QTd (fig 1, table 2) compared with measurements

Table 2 Electrocardiographic effect of terodiline in 12 patients in sinus rhythmn

Figure 1 Corrected $Q T$ intervals $(Q T c)$ and $Q T$ dispersion (QTd) in 12 patients in sinus rhythm on and off terodiline, together with means (SD). Four with means $(S D)$. Four that prolong QTc are shown as crosses.

\begin{tabular}{|c|c|c|c|c|c|}
\hline & $\begin{array}{l}\text { Heart rate } \\
\text { (beats } / \mathrm{min} \text { ) }\end{array}$ & $\begin{array}{l}P R \text { interval } \\
(m s)\end{array}$ & $\underset{(m s)}{Q T \max }$ & $\begin{array}{l}Q T c \\
(m s 1 / 2)\end{array}$ & $\begin{array}{l}Q T d \\
(m s)\end{array}$ \\
\hline $\begin{array}{l}\text { Patients not receiving treatment } \\
\text { Patients receiving treatment } \\
\text { Mean difference } \\
(95 \% \mathrm{CI}) \\
\text { Paired } t \text { test }\end{array}$ & $\begin{array}{l}73(16) \\
72(14) \\
-2 \\
(-10 \text { to } 7) \\
\text { NS }\end{array}$ & $\begin{array}{l}166(22) \\
178(26) \\
12 \\
(-3 \text { to } 26) \\
\text { NS }\end{array}$ & $\begin{array}{l}405(49) \\
456(64) \\
51 \\
(17 \text { to } 85) \\
P<0.01\end{array}$ & $\begin{array}{l}443(33) \\
491(43) \\
48 \\
(23 \text { to } 74) \\
P<0 \cdot 002\end{array}$ & $\begin{array}{l}42(17) \\
84(35) \\
42 \\
(13 \text { to } 70) \\
P<0.01\end{array}$ \\
\hline
\end{tabular}


made when patients were not receiving treatment. There was a positive correlation between absolute values of QTc and QTd in patients receiving terodiline $(r=0.70, \mathrm{P}<$ $0.005)$ and between terodiline induced increases in QTc and QTd $(r=0.88, \mathrm{P}<$ 0.001 ). Increases in QTmax, QTc, and QTd correlated significantly with the plasma concentrations of terodiline and each of its enantiomers (fig 2).

QTc was increased with terodiline in three patients whose electrocardiograms showed controlled atrial fibrillation on and off treatment. QTc was reduced with terodiline in one other patient, but this patient's atrial fibrillation was uncontrolled (rate $110 / \mathrm{min}$ ) when treatment was not given and the QTc is probably invalid at this rate.

\section{Discussion}

The QT interval is an important factor in the genesis of ventricular arrhythmia. QTc prolongation in excess of $500 \mathrm{~ms} /{ }^{1 / 2}$ almost inevitably accompanies torsade de pointes. ${ }^{9}$ More modest prolongation is associated with an increased risk of sudden death in several patient groups. ${ }^{10-12}$ Drugs that prolong the QT interval can cause ventricular arrhythmia and sudden death, for example, antiarrhythmic drugs, phenothiazines, and some antihistamines. ${ }^{5}$ The risk of drug induced arrhythmia, however, is not determined by the QT interval alone; drugs with class III effects such as amiodarone increase QTc but are apparently associated with a low risk of torsade. ${ }^{13}$ Furthermore, evidence of the relation between the risk of sudden death and the QTc interval in apparently healthy populations is conflicting. ${ }^{14} 15$

An important factor in the genesis of arrhythmia is the heterogeneity or dispersion of the duration of ventricular repolarisation. When dispersion is increased some areas of the ventricle will be refractory at times when others can allow unidirectional or bidirectional impulse propogation. This may establish local re-entry circuits and ventricular tachycardia or fibrillation may then be triggered by critically placed ventricular premature contractions. ${ }^{16}$ Indirect evidence suggests that the interlead variability in QT interval durations obtained from the standard 12 lead electrocardiogram reflects increased dispersion of ventricular recovery and the risk of arrhythmia $^{671718}$ and sudden death. ${ }^{19}$ QT interval dispersion does not necessarily increase as the QT interval lengthens: for example, amiodarone prolongs QTc without increasing $\mathrm{QTd}^{9}$ and this may explain its infrequent association with torsade. Early afterdepolarisations also seem to be important in the genesis of torsade and these might also be reflected in the 12 lead electrocardiogram as increased QTd. ${ }^{69}$ It is therefore important that QT interval and dispersion are measured when investigating the effects of drugs on ventricular repolarisation.

Nine of the 10 patients described in the literature who developed torsade de pointes while receiving terodiline had marked prolongation of the QTc interval, ${ }^{3420}$ however, daily terodiline doses were only a little higher (mean $40 \mathrm{mg}$ ) than in our asymptomatic group. Our results and those of a small open study of the effects of terodiline in elderly patients ${ }^{20}$ show that QTc prolongation is common in asymptomatic patients receiving the drug, although this is less marked than in the patients with torsade de pointes. The observation that terodiline also increases the dispersion of ventricular recovery as measured by the QTd has not previously been reported. These effects correlate closely with plasma concentrations of the drug and its enantiomers confirming that this is a type A concentration related adverse drug reaction, although some patients, for example, those with heart disease or hypokalaemia, may be particularly susceptible. Consistent with this, plasma terodiline concentration was substantially higher $(2946 \mathrm{ng} / \mathrm{ml})$ in the one patient with torsade de pointes who had this measured $^{4}$ than in our asymptomatic patients.

Why some patients develop high concentrations of terodiline needs to be clarified. One risk factor is increasing age as elderly patients metabolise terodiline more slowly, with a mean elimination half life of $130-190 \mathrm{~h}^{2122}$ compared with $63 \mathrm{~h}$ in younger patients. ${ }^{23}$ Thus it may take several weeks for steady state plasma concentrations to be achieved and these may be higher than anticipated. In addition, there is considerable variability in the terodiline elimination half life between elderly individuals. ${ }^{2122}$ Variations in clearance probably reflect differences in hepatic metabolism via $p$-hydroxyterodiline, the major route of elimination. This process may be affected by genetic polymorphism as clearance of $R(+)$ terodiline was reduced in a slow hydroxylator of debrisoquine. ${ }^{24}$

The terodiline enantiomers have stereoselective actions. The $R(+)$-enantiomer is a more potent antimuscarinic agent, ${ }^{25} 26$ while the $\mathrm{S}(-)$-enantiomer has more marked calcium antagonist properties. ${ }^{25}$ In rats hydroxylation of the two enantiomers occurs at different rates, being more rapid for $\mathrm{R}(+)$ terodiline. ${ }^{27}$ If this was also true in humans then it would be expected that plasma concentrations of the $\mathrm{S}(-)$ enantiomer would be higher at steady state. In our patients, however, plasma concentrations of each enantiomer were similar, and it is therefore unlikely that differential clearance occurs in humans. This is consistent with a previous observation that clearance of $\mathrm{R}(+)$-terodiline is similar to that of the racemic drug. ${ }^{24}$

This study does not indicate which of the enantiomers is most responsible for the observed electrophysiological effects, nor can it exclude the possibility that these are caused by a metabolite rather than the parent drug. Increases in QTc and QTd correlated significantly with both enantiomers, but the concentrations of the enantiomers are closely related to each other. The most likely mechanism is potassium channel inhibition, a property of other QT prolonging drugs such as quinidine, 
amiodarone, and terfenadine. ${ }^{528}$ To date the effects of terodiline enantiomers on cardiac potassium channels have not been studied.

Important lessons from the terodiline experience should be learned. It is clear from this and other data that if an effect of the drug on cardiac repolarisation had been sought during its development it would have been detected. This would have limited the use of the drug in high risk groups and resulted in closer monitoring of patients while receiving therapy. In view of the close structural similarity to the proarrhythmic drug prenylamine ${ }^{29}$ it is disappointing that electrocardiographic effects were not studied. Nevertheless it is reassuring that voluntary organised adverse drug reaction reporting by prescribers in the United Kingdom detected and characterised the problem.

Studies using isolated detrusor muscle strips suggest that the beneficial effects of terodiline on the bladder are primarily mediated by the anticholinergic $R(+)$-enantiomer. ${ }^{26}$ If the adverse cardiovascular effects are caused by the $S(-)$-enantiomer then treatment with pure $\mathbf{R}(+)$-terodiline might have an acceptable risk-benefit ratio. Studies to characterise further the electrophysiological effects of terodiline enantiomers in animals and humans would be useful.

We are grateful to Kabi Pharmacia for supplies of racemic terodiline and its enantiomers, and to members of the urolog department at the Freeman Hospital for their help with the study.

1 Andersson K-E. Clinical pharmacology of terodiline. Scand f Urol Nephrol 1984;87(suppl):13-20

2 Langtree HD, McTavish D. Terodiline: a review of its pharmacological properties and therapeutic use in the treatment of urinary incontinence. Drugs 1990;40: 748-61.

3 McCloud AA, Thorogood S, Barnett S. Torsade de pointes complicating treatment with terodiline. $B M^{\mathscr{F}}$ 1991;302:1469.

4 Connolly MJ, Astrige PS, White EG, Morley CA Campbell Cowan J. Torsades de pointes ventricular tachycardia and terodiline. Lancet 1991;338:344-5.

5 Thomas SHL. Drugs, QT interval prolongation and ventricular arrhythmias. Adv Drug React Tox Rev 1994; 13:77-102.

6 Higham PD, Campbell RWF. QT dispersion. Br Heart $\mathcal{f}$ 1994;71:508-10

7 Day CP, McComb JM, Campbell RWF. QT dispersion: an indication of arrhythmia risk in patients with long $Q T$ intervals. Br Heart $₹$ 1990;63:342-44.

8 Zehender M, Hohnloser S, Just H. QT-interval prolonging drugs: mechanisms and clinical relevance of their arrhythmogenic hazards. Cardiovascular Drugs $\mathcal{E}$ Therapy 1991;5:515-30.
9 Hii JTY, Wyse DG, Gillis AM, Duff HJ, Solyo MA Mitchell LB. Precordial QT interval dispersion as a marker of torsade de pointes. Disparate effects of class 1a antiarrhythmic drugs and amiodarone. Circulation 1992;86:1376-82.

10 Laakso M, Åberg $\AA$, Savola J, Pentikälinen PJ, Pyörälä K. Diseases and drugs causing prolongation of the QT interval. Am $\mathcal{F}$ Cardiol 1987;59:862-5.

11 Algra A, Tijssen GP, Roeland RTC, Pool J, Lubsen J. QTc prolongation measured by standard 12 lead electrocardiography is an independent risk factor for sudden death due to cardiac arrest. Circulation 1991;83 1888-94.

12 Fioretti P, Tijssen GJP, Azar Lazzeroni E, et al. Prognostic significance of predischarge 12 lead electrocardiogram after myocardial infarction compared with other routine clinical variables. Br Heart f 1987;57:306-12.

13 Mattioni TA, Heutlin TA, Sarmiento JJ, Parker M, Lesch $M$, Kehoe RF. Amiodarone in patients with previous drug-mediated torsade de pointes: long term safety and efficacy. Ann Intern Med 1989;111:574-80.

14 Goldberg RJ, Bengtson J, Chen Z, Anderson KM, Locat E, Levy D. Duration of the QT interval and total cardiovascular mortality in healthy persons (the Framingham study experience). Am $₹$ Cardiol 1991;67:55-8.

15 Schoeten EG, Dekker JM, Meppelink P, Kok FJ, Vandenbroucke JP, Pool J. QT interval prolongation Vandenbroucke JP, Pool J. QT interval prolongation predicts cardiovascular mortality in an app

16 Han J, Millet D, Chizzonette B, et al. Temporal dispersion of recovery of excitability in atrium and ventricle as function of heart rate. Am Heart $\mathcal{F}$ 1966;76:481-90.

17 Day CP, McComb JM, Campbell RWF. QT dispersion in sinus beats and ventricular extrasystoles in normal hearts. Br Heart $\mathcal{F}$ 1992;67:266-8.

18 Day CP, McComb JM, Mathews J, Campbell RWF. Reduction in QT dispersion by sotalol followin myocardial infarction. Eur Heart f 1991;12:423-7.

19 Barr CS, Naas A, Freeman N, Lang CC, Struthers AD. QT dispersion and sudden unexplained death in chronic heart failure. Lancet 1994;343:327-9.

20 Stewart DA, Taylor J, Ghosh S, et al. Terodiline cause polymorphic ventricular tachycardia due to reduced heart rate and prolongation of QT interval. Eur $₹ \mathrm{Clin}$ Pharmacol 1992;42:577-80.

21 Hallén B, Magnusson A, Bogentoft S, Ekelund P. Singleand multiple-dose pharmacokinetics of terodiline in geriatric patients. Eur 7 Clin Pharmacol 1988;34:291-7.

22 Hallén B, Bogentoft $S$, Sandquist $S$, Stromberg $S$ Setterberg G, Ryd-Kjelen E. Tolerability and steady state pharmacokinetics of terodiline and its main state pharmacokinetics of terodiline and its main
metabolites in elderly patients with urinary incontinence. Eur f Clin Pharmacol 1989;36:487-93.

23 Karlen B, Andersson K-E, Ekman G, Stromberg S Ulmsten U. Pharmacokinetics of terodiline in huma volunteers. Eur $\mathcal{F}$ Clin Pharmacol 1982;23:267-70.

24 Hallén B, Gabrielsson B, Palmer J, Ekstrom B. Pharmacokinetics of $\mathrm{R}-(+)$-terodiline given intravenously and orally to healthy volunteers. Pharmacol Toxicol 1993;73:153-8.

25 Irson-Backström C, Arrenius E, Sagge K. Comparison of the calcium-antagonistic effects of terodiline, nifedipin and verapamil. Acta Pharmacologica \& Toxicologica 1985 57:8-17.

26 Andersson K-E, Ekström B, Mattiasson A. Actions of terodiline, its isomers and main metabolite on isolate detrusor muscle from rabbit and man. Acta Pharmacol $\&$ Toxicol 1988;63:390-5.

27 Lindeke B, Ericsson Ö, Jönsson Å, Noren B, Strömberg S, Vangbo B. Biotransformations of terodiline. III Opposed stereoselectivity in the benzylic and aromatic hydroxylations in rat liver microsomes. Xenobiotica 1987;17:1269-78.

28 Woosley RL, Chen Y, Freiman JP, Gillis RA. Mechanism of the cardiotoxic actions of terfenadine $¥ A M A 1993 ; 269$ : 1532-6.

29 Puritz R, Henderson MA, Baker SN, Chamberlain DA. Ventricular arrhythmias caused by prenylamine. $B M$ 1977;2:608-9. 